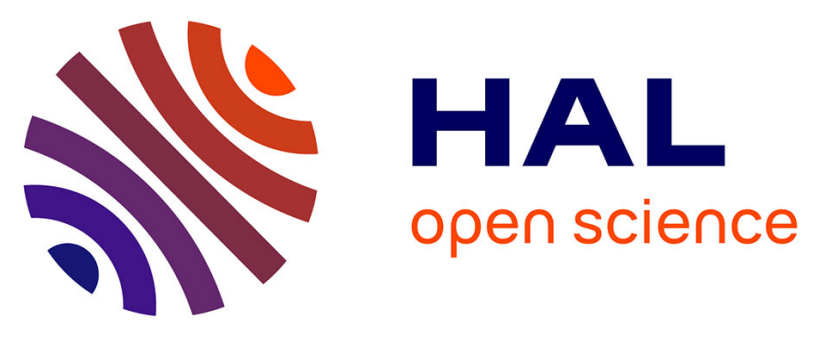

\title{
Acromegaly: presentation, morbidity and treatment outcomes at a single centre
}

Panagiotis Anagnostis, Zoe Efstathiadou, Stergios Polyzos, Fotini Adamidou, Aristidis Slavakis, Michalis Sapranidis, Ioannis Litsas, Simoni Katergari, Despina Selalmatzidou, Marina Kita

\section{To cite this version:}

Panagiotis Anagnostis, Zoe Efstathiadou, Stergios Polyzos, Fotini Adamidou, Aristidis Slavakis, et al. Acromegaly: presentation, morbidity and treatment outcomes at a single centre. International Journal of Clinical Practice, 2011, 65 (8), pp.896. 10.1111/j.1742-1241.2011.02682.x . hal-00652661

\section{HAL Id: hal-00652661 https://hal.science/hal-00652661}

Submitted on 16 Dec 2011

HAL is a multi-disciplinary open access archive for the deposit and dissemination of scientific research documents, whether they are published or not. The documents may come from teaching and research institutions in France or abroad, or from public or private research centers.
L'archive ouverte pluridisciplinaire HAL, est destinée au dépôt et à la diffusion de documents scientifiques de niveau recherche, publiés ou non, émanant des établissements d'enseignement et de recherche français ou étrangers, des laboratoires publics ou privés. 


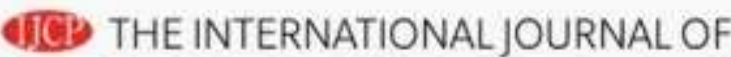 CLINICAL PRACTICE}

\section{Acromegaly: presentation, morbidity and treatment outcomes at a single centre}

\begin{tabular}{|r|l|}
\hline Journal: & International Journal of Clinical Practice \\
\hline Manuscript ID: & IJCP-01-11-0015.R1 \\
\hline Datey - Manuscript type: & Original Paper \\
\hline Author: & $19-$-Feb-2011 \\
\hline & $\begin{array}{l}\text { Anagnostis, Panagiotis; Aristotle University of Thessaloniki, , 2nd } \\
\text { Propedeutic Department of Internal Medicine } \\
\text { Efstathiadou, Zoe; "Hippocration" General Hospital of Thessaloniki, } \\
\text { Endocrinology } \\
\text { Polyzos, Stergios; Medical School, Aristotle University of } \\
\text { Thessaloniki, Hippokratio General Hospital, Second Medical Clinic } \\
\text { Adamidou, Fotini; Hippokration Hospital, Endocrinology Clinic } \\
\text { Slavakis, Aristidis; "Hippokration" General Hospital of Thessaloniki, } \\
\text { Department of Microbiology } \\
\text { Sapranidis, Michalis; Hippokration Hospital, Endocrinology Clinic } \\
\text { Litsas, Ioannis; Hippokration Hospital, Endocrinology Clinic } \\
\text { Katergari, Simoni; Hippokration Hospital, Endocrinology Clinic } \\
\text { Selalmatzidou, Despina; Hippokration Hospital, Endocrinology; } \\
\text { Hippokration Hospital, Endocrinology Clinic } \\
\text { Kita, Marina; Hippokration Hospital, Endocrinology Clinic }\end{array}$ \\
\hline Specialty area: & \begin{tabular}{l} 
\\
\hline
\end{tabular} \\
\hline
\end{tabular}

\section{SCHOLARONE" Manuscripts}


Dr. Graham Jackson

Editor-in-Chief

International Journal of Clinical Practice

Saturday, 19 February 2011

Re: Revision of manuscript IJCP-01-11-0015 by Anagnostis et al

Dear Sir,

We were pleased to hear that the International Journal of Clinical Practice is interested in a revised version of our work. We are thankful to the reviewers for their constructive comments. We have addressed all their suggestions in this revised version. In more detail:

Reviewer: 1

1. For the patients who received radiotherapy, it would be useful to know what the radiation dose was.

The radiation dose was the standard 45Gy divided in 25 doses. This is now stated at the text, p10, $2^{\text {nd }}$ paragraph, line 1: "Conventional radiotherapy -at a standard dose of 45 Gy in 25 fractions-..."

2. Regarding the morbidity associated with acromegaly at follow up (page 8). Did these co-morbidities develop during the FU period or they were discoverd then because the patients were not examined for these at presentation?

The data presented under the header "At baseline" in page 8 refer to morbidity discovered at baseline. Because there were missing values, for further clarity, we have added the number of patients who were actually examined for each co-morbidity at presentation in $\mathrm{p} 8,2^{\text {nd }}$ paragraph, lines 5-8: “.....(data available for 84$)$. Data on glucose homeostasis were available for 87 patients at presentation and were diagnostic for DM in $25 \%$, for impaired glucose tolerance (IGT) in another $25 \%$. Dyslipidemia was present in 35\% (data available in 60 subjects)."

3. DA treatment: the authors should explain the abbreviation.

DA stands for dopamine agonists. We have added the definition the first time it appears in the text: page $10,2^{\text {nd }}$ paragraph, line 6 . 


\section{Reviewer: 2}

General and specific comments to the authors

In this retrospective study are reported the clinical characteristics, the efficacy of treatment, and the morbidity in a cohort of 115 acromegalic patients with mean follow-up 8.8 years from a single center in Greece. These data are valuable though the number of patients is relatively small. However there are some points that should be stressed.

1. The assessment of good disease control is based on targets, which have been set by consensus. However, since epidemiological studies have shown that active acromegaly is associated with increased mortality the targets that establish the remission of the disease have recently changed, as you also have mentioned in the text. For the sake of clarity for the reader I consider that the recent guidelines should follow the previous ones.

We acknowledge that comment and we make a comment about the previous guidelines before the most recent ones in page 5, 1 st paragraph, lines 2-4: "Till recently, the consensus guidelines for acromegaly cure recommended normal age- and sex-adjusted IGF-I levels, along with a nadir $\mathrm{GH}<1 \mu \mathrm{g} / \mathrm{L}$ during an OGTT, irrespective of concurrent treatment (6). The latest....."

2. It is known that the lack of reliable assays for serum GH and IGF-1 measurements is a major issue in the interpretation of the results. Therefore it is important to be presented the characteristics of the assays used regarding at least the used standard and their sensitivity.

We acknowledge the reviewer's comment and we have inserted a paragraph in the methods section, page $6,2^{\text {nd }}$ paragraph, lines 6-8:

"The detection limits and assay analytical sensitivity for ICMA method are $0.05-40 \mathrm{ng} / \mathrm{ml}$ and $0.01 \mathrm{ng} / \mathrm{ml}$ respectively for $\mathrm{GH}$ and $0.00-1600 \mathrm{ng} / \mathrm{ml}$ and $20 \mathrm{ng} / \mathrm{ml}$ for IGF-I."

3. Authors comment on the importance of an experienced surgeon and speculate that the results of their series could be better if they had an experienced pituitary neurosurgeon. This raises a question about the neurosurgeon's experience and skillful. This lack of clearness should be resolved.

We have added a new reference on the subject and two sentences clarifying the matter in page $14,2^{\text {nd }}$ paragraph, lines 2-6: "A recent review has shown that focused clinical practice and large transsphenoidal surgical volume appear to be important outcome determinants for patients with pituitary tumors (19). The fact that in our country there is no regionalization of care to higher volume pituitary tumor centers of excellence is a major drawback to better surgical outcomes. Consequently....."

4. The role of SSA therapy in achieving tumor shrinkage is not well defined. Some data in the literature indicate that the presurgical use of SSA may improve surgical outcome. Is there any evidence in your data regarding this issue?

Since there were only 7 patients who received pharmacotherapy prior to surgery, no safe conclusions can be drawn for that matter.

5. Conventional radiotherapy is usually used as an adjuvant therapy in pituitary 
adenomas secreting GH. However, its beneficial effect appears progressively over years. It would be interesting to comment on this in your cohort.

We comment that in the discussion session: page16, last paragraph, lines 1-2. To further clarify that we have added the sentence: "Conventional radiotherapy is usually used as an adjuvant therapy in pituitary adenomas secreting GH. However, its beneficial effect appears progressively over years", at the beginning of the same paragraph.

Furthermore, the time of remission is described in the sentence (lines 7-9): "It must be noted that radiotherapy outcomes were manifest at 12-34 years of follow-up, except for 1 patient, who had already achieved remission at 7 years."

6. Two inconsistencies are noticed in Table 1; In the second row "surgery alone" it appears that from the 22 patients, remission was achieved in 9 patients but this number is not equal to the sum of micro- and macroadenomas in remission (last two columns). The same inconsistency is also observed in the fourth row "Surgery/Radiotherapy"

This inconsistency is due to the fact that the initial size was not available in 2 patients, 1 treated with surgery alone and 1 with surgery/radiotherapy. Both achieved remission, as it is stated in the comments at the bottom of the table 1. (We have corrected surgery/pharmacotherapy to surgery/radiotherapy (comments in table 1).

We thank you again for the constructive comments, which were contributed to our manuscript. Having addressed all these comments we hope that the revised manuscript would be acceptable for publication at the International Journal of Clinical Practice.

Sincerely,

Zoe Efstathiadou 


\title{
Acromegaly: presentation, morbidity and treatment outcomes at a single centre
}

\author{
Panagiotis Anagnostis ${ }^{1}$, Zoe A Efstathiadou ${ }^{1}$, Stergios A Polyzos ${ }^{1}$, Fotini Adamidou ${ }^{1}$, \\ Aristides Slavakis ${ }^{2}$, Michalis Sapranidis ${ }^{1}$, Ioannis D Litsas ${ }^{1}$, Simoni Katergari ${ }^{1}$, \\ Despina Selalmatzidou ${ }^{1}$, Marina Kita ${ }^{1}$ \\ ${ }^{1}$ Department of Endocrinology, "Hippokration" General Hospital of Thessaloniki, \\ Thessaloniki, Greece \\ ${ }^{2}$ Department of Microbiology, Hormone Assay Laboratory, "Hippokration" General \\ Hospital of Thessaloniki, Thessaloniki, Greece
}

Short title: Acromegaly: a single centre experience

Key words: Acromegaly; Growth hormone; Insulin-like growth factor-1; Transsphenoidal surgery; Somatostatin analogues

Word count: Abstract 250, Text 3441, Tables 2, Figures 0

\section{Corresponding Author:}

Dr Zoe Efstathiadou, PhD

Department of Endocrinology,

"Hippokration" General Hospital of Thessaloniki,

49 Konstantinoupoleos str

Thessaloniki, 54642 GREECE

Phone: 00302310892269

Fax: 00302310848453

E-mail: zefsta@endo.gr

Conflict of interest: The authors have no conflict of interest to disclose 


\section{Abstract}

Objective: Analysis of patients with acromegaly followed-up at a single centre, focusing on baseline characteristics, morbidity, and efficacy of treatment.

Design and methods: Retrospective review of electronic medical records of acromegalics from 1987 to 2009.

Results: One-hundred and fifteen patients (45 men), aged $47 \pm 14$ years, with a mean follow-up of $8.8 \pm 0.8$ years were studied. Twenty-five percent had micro- and $75 \%$ macroadenomas. Forty-three percent presented with visual field defects, $49 \%$ had hypertension, $25 \%$ diabetes mellitus and 35\% dyslipidemia, 50\% myocardial hypertrophy, 55\% colon polypodiasis, 74\% nodular thyroid disease and $18 \%$ adrenal masses. Surgery was performed in $79 \%$ ( $8 \%$ twice), followed by conventional radiotherapy in $27 \%$.

Fifty-two percent of the patients achieved remission. Disease control was reported in $65 \%$ of microadenomas and $41 \%$ of macroadenomas. Remission rates with surgery alone were $41 \%$. Impovement of remission rates was achieved with subsequent treatment with somatostatin analogues (SSA) $(53 \%)$, or conventional radiotherapy (63\%). Nevertheless, pituitary reserve was compromised with the latter. SSA significantly improved outcomes in microadenomas, even as a monotherapy (remission in $89 \%$ ), in contrast to macroadenomas $(0 \%)$, although these agents were associated with impaired glucose metabolism and cholelithiasis in half of the cases.

Conclusions: Acromegaly is associated with increased morbidity. About half of the treated patients achieved remission ( $2 / 3$ of microadenomas). The best outcomes were reported for the combination of surgery with radiotherapy, in spite of a higher risk of hypopituitarism. SSA led to remission in a significant percentage of microadenomas, 
but were associated with increased rates of cholelithiasis and impaired glucose homeostasis.

\section{What's known:}

- Acromegaly is a rare chronic disease characterized by hypersecretion of GH, which leads to an increased production of IGF-I.

- Acromegaly is associated with significant morbidity and an increased mortality rate.

- Transsphenoidal surgery is the first line treatment for acromegaly. In case of persisting disease treatment with somatostatin analogues and/or radiotherapy (conventional or $\gamma$-knife) are applied.

\section{What's new:}

- Neurosurgery alone is not effective for disease control in the majority of cases.

- Medical therapy with SSA, either as adjuvant to surgery, or as monotherapy is effective, but might have unfavourable side-effects, such as impaired glusose homeostasis and cholelithiasis.

- Remission of the disease is usually achieved by combination of multiple treatment modalities. 


\section{Introduction}

Acromegaly is a rare chronic disease characterized by hypersecretion of GH which leads to an increased production of IGF-I (1-2). In the majority of cases $(>95 \%)$ it results from a GH-secreting pituitary adenoma (1-2).

The incidence of acromegaly is about 3 cases per million persons with an estimated prevalence of 60 per million (3). The disease onset takes place during the $4^{\text {th }}$ decade of life with an equal distribution between genders (1-2).

Acromegaly affects almost every organ and is associated with increased morbidity and mortality mainly due to the aggregate of cardiovascular risk factors such as hypertension, diabetes mellitus (DM) and lipid disorders and to the appearance of cardiomyopathy associated with the disease (4). In a recent meta-analysis of 16 series, the mortality ratio of patients with acromegaly was 1.72 compared with the general population, and remained high (1.32) even after surgical management of the disease (5).

Despite the progress that has been made over the years in terms of therapeutic modalities, acromegaly still remains under-diagnosed, with a mean delay of 7-10 years after the estimated onset of symptoms (1-2). The introduction of highly sensitive and specific GH assays has recently led to a re-evaluation of the biochemical criteria needed for the diagnosis of acromegaly. This is based on nadir GH levels $>1$ $\mu \mathrm{g} / \mathrm{L}$ during an oral glucose tolerance test (OGTT) in combination with IGF-I above the upper level of normal for age and sex (1-2).

Although remarkable advances in terms of the medical management of the disease have been made, transsphenoidal surgery (TSS) remains the treatment of choice resulting in disease control in $75-95 \%$ of patients harbouring microadenomas and in $40-68 \%$ of those with macroadenomas $(1-2,6)$. In case of persisting disease after 
surgical and medical approach, radiotherapy (conventional or $\gamma$-knife) is a reasonable approach $(1-2,6)$. Till recently, the consensus guidelines for acromegaly cure recommended normal age- and sex-adjusted IGF-I levels, along with a nadir $\mathrm{GH}<1$ $\mu \mathrm{g} / \mathrm{L}$ during an OGTT, irrespective of concurrent treatment (6). The latest guidelines for acromegaly cure recommend random $\mathrm{GH}<1 \mu \mathrm{g} / \mathrm{L}$ or nadir $\mathrm{GH}<0.4 \mu \mathrm{g} / \mathrm{L}$ during an OGTT combined with age- and sex-adjusted normal IGF-I levels (7). If IGF-I and GH are elevated, additional therapy should be considered (6-7). In case of discordant IGF-I and GH measurements -in most cases normal GH and elevated IGF-I (7), the decision for acromegaly management should be based on clinical judgement (6). In these cases, multiple GH sampling is also recommended (7).

The aim of the present study was to describe the clinical characteristics, the morbidity and the efficacy of treatment in a cohort of patients with acromegaly, who were followed-up at a single centre.

\section{Patients and methods}

This was a retrospective study conducted in the department of Endocrinology in "Hippokration" General Hospital of Thessaloniki, Greece, a tertiary referral centre for endocrinology and diabetes. Data from all patients who were diagnosed with acromegaly or referred to the centre with the diagnosis of acromegaly between 1987 and 2009 were extracted from the department's electronic database and thoroughly reviewed. Inclusion criteria were: 1) abnormal nadir GH levels ( $>1 \mu \mathrm{g} / \mathrm{L})$ during a 75 g OGTT along and/or abnormal IGF-I levels for age and gender 2) imaging characteristics suggestive of a pituitary adenoma 3) at least 1 complete clinical and biochemical assessment. Disease remission was defined by normal IGF-I for sex and age along with nadir $\mathrm{GH}<1 \mu \mathrm{g} / \mathrm{L}$, for $\mathrm{GH}$ measurements after the year of 2000 , when 
the criteria for cure of acromegaly changed (8). For the years 1987-1999, a cut-off value for nadir GH of $2 \mu \mathrm{g} / \mathrm{L}$ was used. In case of discordant IGF-I and GH results, the decision for further therapeutic interventions was based on clinical judgment.

The assays used for GH measurement changed over the years. For the period 1987-1999, radioimmunoassay (RIA) was used, while from 2000 and thereafter GH was measured by an immunochemiluminencent assay (ICMA) (Immulite 2500, DPC, Los Angeles, USA). ICMA was also used for IGF-I assessment from 2000 to 2009, while before 2000, it was measured using enzyme-linked immunosorbent assay (ELISA). The detection limits and assay analytical sensitivity for ICMA method are $0.05-40 \mathrm{ng} / \mathrm{ml}$ and $0.01 \mathrm{ng} / \mathrm{ml}$ respectively for $\mathrm{GH}$ and $0.00-1600 \mathrm{ng} / \mathrm{ml}$ and $20 \mathrm{ng} / \mathrm{ml}$ for IGF-I.

All patients underwent physical examination, visual field perimetry and basal biochemical assessment. In addition, laboratory evaluation of the other pituitary hormones was performed in order to unmask potential pituitary deficiencies: LH/FSH, ACTH, TSH, both before and after surgical intervention. In case of signs and symptoms of hypopituitarism, stimulation tests were performed. Gonadotrophin deficiency was defined as low or 'inappropriately normal' LH and FSH levels combined with serum testosterone and serum oestradiol below the reference range or inadequate response to (LH-Releasing Hormone) LHRH test. ACTH deficiency was detected in case of an insufficient increase $(<18 \mu \mathrm{g} / \mathrm{dl})$ in cortisol levels during a cosyntropin-stimulation test or a glucagon-stimulation test. TSH-deficiency was determined by low or 'inappropriately normal' TSH with thyroid hormone levels (free $\mathrm{T} 4$ and/or free $\mathrm{T} 3$ ) below the normal range.

The patients were revaluated at 6- to 12-month intervals by clinical, routine biochemical laboratory and hormonal (IGF-I and GH levels during an OGTT) 
examination and by MRI. CT was the only means available for pituitary imaging before 1993. Shorter intervals between follow-up visits were applied in cases of significant alterations in clinical status or changes in therapeutic regimen. Macroadenomas were defined as those with maximum diameter $>1 \mathrm{~cm}$, and microadenomas when maximum diameter was $\leq 1 \mathrm{~cm}$. The duration of follow-up was estimated as the time between the first and last GH secretion assessment.

\section{Statistical analysis}

Data for continuous variables are presented as mean \pm standard error of the mean (SE). Data for categorical variables are presented as numbers and/or percentages. Kolmogorov-Smirnov test was used to check the normality of distribution of continuous variables. Chi-square test or Fischer's exact test were used to identify differences between categorical variables. Independent-sample T-test or MannWhitney test was used to identify differences between two independent groups of continuous variables. The analysis of variance (ANOVA) or Kruskal-Wallis test were used to identify differences among three or more groups of continuous variables. The General Linear Model (GLM) (repeated measures ANOVA) was used to identify differences within continuous variables in cases of serial measurements. Adjustment for violations of the sphericity assumption was performed with the GreenhouseGeisser correction. Bivariate correlations were tested by Pearson's (r) or Spearman's $\left(r_{s}\right)$ coefficients of correlation. A $p$ value less than 0.05 was considered statistically significant in all the above tests. Statistical analysis was performed with SPSS 13.0 for Windows (SPSS Inc., Chicago, Illinois, USA).

\section{Results}

\section{$\underline{\text { Patient characteristics }}$}


Three hundred and ninety-three patients were retrieved from our electronic database with a pituitary adenoma. One hundred and fifteen patients (45 males and 70 females) met the study's criteria.

The mean age at diagnosis was $47 \pm 1$ years (range 14-84). The mean size of adenomas was $1.7 \pm 0.1 \mathrm{~cm}$ (range $0.4-4.0) ; 26 \%$ were microadenomas and $74 \%$ macroadenomas with extrasellar extension in $44 \%$. In 2 cases acromegaly was detected on radiological examination performed for signs/symptoms unrelated to pituitary disease, that is, head trauma in one case and stroke in the other. There was a strong correlation between GH and nadir $\mathrm{GH}(\mathrm{r}=0.961, \mathrm{p}<0.001)$ at baseline.

Both GH and nadir GH were also correlated with adenoma size $(r=0.293, p=0.030$ and $\mathrm{r}=0.324, \mathrm{p}=0.020$, respectively). The mean duration of follow-up was $8.8 \pm 0.8$ years (range 0-22). Follow-up data for $\geq 12$ months were available for 93 patients.

\section{Morbidity associated with acromegaly}

At baseline

At presentation, visual field defects were detected in 36 of the 84 cases (43\%) whose perimetry tests were available. Five patients (14\%) with visual disorders were harbouring microadenomas with diameter $0.9-1 \mathrm{~cm}$.

In terms of acromegaly-related morbidity, $46 \%$ of the patients presented with arterial hypertension (data available for 84). Data on glucose homeostasis were available for 87 patients at presentation and were diagnostic for DM in $25 \%$, for impaired glucose tolerance (IGT) in another 25\%. Dyslipidemia was present in 35\% (data available in 60 subjects).

At follow-up

Of the 93 acromegalic patients with available follow-up data, $10(11 \%)$ were diagnosed with coronary artery disease and 46 (50\%) had cardiac hypertrophy on 
echocardiography. Fifty-five percent of those undergoing colonoscopy had polypodiasis, $74 \%$ mono- or multinodular thyroid disease assessed by ultrasonography and $18 \%$ of those submitted to abdominal CT or MRI were harbouring an adrenal mass.

Cholelithiasis was detected in 20 of 44 patients examined by ultrasound of the upper abdomen. Notably, the majority $(90 \%)$ of patients with gallstones had received SSA treatment. The frequency of cholelithiasis in patients on SSA treatment was 53\% (18 of 34 patients who underwent ultra-sound).

Glucose homeostasis was assessed in 45 patients who were given SSA pharmacotherapy. Twenty four patients with abnormal glucose homeostasis (IGT or $\mathrm{DM})$ at baseline received SSA and glucose control deteriorated in 8 , improved in another 8 and remained stable in the rest. On the other hand, 11 out of 21 euglycaemic patients at baseline developed IGT or DM after SSA administration. These data for glucose metabolism were independent of disease remission.

\section{$\underline{\text { Treatment }}$}

\section{Surgical treatment}

Pituitary surgery was performed in 73 patients with follow-up data (79\%). Of these, $6(8 \%)$ were operated twice, due to uncontrolled or recurrent disease. The majority of the surgical procedures $(n=64,88 \%)$ were performed by the transsphenoidal route. In 10 cases with invasive tumours, transcranial surgery was selected- in 2 of them secondary to transsphenoidal approach. In 1 case the surgical approach was not known. Except for the tumour's size and the invasion into neighbouring structures, the choice of surgical approach was also based on neurosurgeon's experience. 
Twenty-two patients were exclusively managed with neurosurgery and remission was reported in 9 (41\%). Three had microadenomas and 5 macroadenomas, while initial size was not available in 1 . Interestingly, only 1 in 6 macroadenomas with extrasellar extension achieved remission after surgery alone. In 1 patient managed successfully with surgery alone initial size was unknown (table 1).

\section{Radiotherapy}

Conventional radiotherapy -at a standard dose of 45 Gy in 25 fractions- was selected for 27 patients (29\%) either as monotherapy or adjuvant to either surgery or SSA. It involved macroadenomas in 24 cases. In general, remission was observed in 14 irradiated patients $(52 \%)$. Twenty patients $(27 \%$ of the surgically treated) received conventional radiotherapy post-surgically, either alone or in combination with pharmacotherapy [mainly SSA and/or dopamine agonists (DA)], while 1 patient was managed with $\gamma$-knife plus SSA postoperatively.

Remission was reported in 5 of the 8 patients $(63 \%)$ who received radiotherapy as adjuvant to neurosurgery. On the other hand, in a total of 12 patients with refractory disease, where SSA treatment was necessary after surgery and radiotherapy, only 4 finally responded. (table1).

\section{Pharmacotherapy}

Pharmacotherapy was the exclusive treatment in 13 patients ( 9 micro- and 4 macroadenomas). SSA were the agents of choice with the exception of 2 patients who received DA. Lack of compliance and/or patient's refusal was the reason for not selecting SSA in these patients.

DA treatment was not successful. On the contrary, SSA treatment led to remission in 8 patients ( $73 \%$ of those exclusively on SSA). It is noteworthy that all the responders had microadenomas, whereas no macroadenoma achieved remission with SSA alone. 
Additionally, pharmacotherapy alone resulted in a decrease in size in 3 of 13 adenomas, (2 with SSA and 1 with DA).

Treatment with pegvisomant either alone or in combination with SSA was preserved for 4 patients ( 2 males and 2 females) with refractory disease, after having undergone surgical therapy, radiotherapy and SSA administration. Two patients achieved remission at 6-8 months of follow-up, at a daily dose of $10 \mathrm{mg}$ as monotherapy, whereas the other 2 , despite being on a combination regimen with SSA, have persistently active acromegaly.

Combination of neurosurgery and pharmacotherapy was reported in 30 patients: in 7 prior to surgery, in 13 post-surgery and in 10 both pre- and postsurgery. Two patients received DA treatment, whereas the rest were treated with SSA. Remission was achieved in $16(53 \%)$. In particular, $100 \%$ of microadenomas $(n=8)$ and $43 \%(n=6)$ of macroadenomas managed with this approach showed no evidence of active disease during follow-up (table 1).

\section{Effect of different treatment modalities on adenoma size, visual fields and pituitary}

\section{function}

\section{Adenoma size and GH/IGF-1 levels}

With respect to adenoma size, 11 of 17 microadenomas (65\%) and 21 of 53 macroadenomas (40\%) achieved tumour shrinkage after surgery (alone or with concomitant radiotherapy or pharmacotherapy) $(\mathrm{p}=0.081)$. Baseline adenoma size was not available in 2 cases.

Disease remission was independent of the tumour invasiveness: remission was achieved in 8 cases $(38 \%)$ with extrasellar extension, compared with 6 cases $(38 \%)$ in which adenoma growth was limited in the sellar space $(p=0.97)$. 
Patients who achieved remission had significantly smaller adenomas at baseline compared with those who did not $(1.3 \pm 0.2$ vs. $1.7 \pm 0.1$, respectively, $\mathrm{p}=0.014)$.

During the first 5 years, GH, IGF-1 and tumor size decreased significantly. The changes in $\mathrm{GH}, \mathrm{GH}_{\text {nadir, }}$ IGF-I and adenoma size during a 5 year follow-up are presented in table 2. However, no significant association was observed between baseline $\mathrm{GH}(\mathrm{p}=0.28)$, nadir $\mathrm{GH}(\mathrm{p}=0.227)$ or IGF-I $(\mathrm{p}=0.512)$ and treatment outcomes.

\section{Visual field defects}

Twenty-five patients with visual field defects were operated and 14 showed improvement postoperatively. Another 5 patients received only pharmacotherapy, which resulted in better perimetry tests in 2 . Among the three patients who were managed exclusively with pituitary irradiation only 1 had a positive response in vision. Follow-up data regarding changes in visual disorders were absent in 6 patients.

\section{Pituitary reserve}

Post-treatment, partial or total hypopituitarism was detected in 33 cases, in contrast with the finding of only 8 cases of hypopituitarism at baseline $(\mathrm{p}=0.001)$. Post-surgery, after the exclusion of patients submitted to complementary conventional radiotherapy or radiosurgery, 16 patients developed hypopituitarism. Interestingly, none of 7 patients treated with radiotherapy alone or plus SSA presented hypopituitarism during follow-up.

\section{Discussion}

This retrospective study outlines the actual presentation and management of acromegalic patients at a single endocrine centre in Greece. 
The acromegalics in the present cohort had increased morbidity in keeping with previous series. However, more patients were reported to have arterial hypertension than in other European registries: $46 \%$ vs. $39 \%$ in both the Belgian (9) and the Spanish (10) studies. In addition, higher rates of cholelithiasis were reported after SSA treatment: $53 \%$ vs. $31 \%$ in Acrobel (9) and $15 \%$ in REA (10). This observation might reflect the very strict selection of patients for ultrasound testing. Furthermore, diabetes onset after SSA was reported in $45 \%$, a little bit higher than in the REA registry.

The aims of therapy in acromegaly are suppression of GH hypersecretion, normalization of IGF-I levels and control of tumor size, as well as preservation of normal pituitary function. Using the aforementioned criteria, the overall success rate in our series was $52 \%-65 \%$ for microadenomas and $41 \%$ for macroadenomas. These percentages are in close proximity with the rates presented in Acrobel (49\%) (9) and in West Midlands studies (46\%) (11).

Although the number of patients was small for drawing safe conclusions for the effectiveness of surgery, this approach was not proven successful as exclusive therapeutic means for most patients. Remission was achieved in 34 (48\%) patients who underwent surgery. Only $50 \%$ of microadenomas and $33 \%$ of macroadenomas (none of those with extrasellar extension) were in remission after surgery. This is in accordance with other "real life" observational series (9). Surgical series that adopted the current remission criteria - nadir $\mathrm{GH}<1 \mu \mathrm{g} / \mathrm{L}$ and/or postoperative random $\mathrm{GH}$ levels $\leq 2.5 \mu \mathrm{g} / \mathrm{L}$ and normal sex- and age-adjusted IGF-I level- have reported remission rates of $52-70 \%(12-14)$. The timing of post-surgical GH status evaluation seems to play a capital role on the outcome, since higher cure rates are reported short term after pituitary surgery and tend to dramatically weaken with time (15). In our 
series, when surgery was followed by medical treatment or radiotherapy the remission rate increased to $53 \%$ and $63 \%$ respectively.

The outcomes of surgical intervention are mainly dependent on initial adenoma size and preoperative basal GH levels. In particular, an inverse relationship between surgical outcomes and adenoma size as well as basal GH levels has been described $(14,16)$.

Remission rates have been reported in $75-95 \%$ of microadenomas and in $40-71 \%$ of macroadenomas $(14,16)$. Extrasellar tumour growth and dural invasion by the adenoma are associated with poor outcomes (about 30\%) $(14,16)$. Regarding the impact of basal GH levels on surgical outcomes, different thresholds have been used and, in general, remission rates are about $86-90 \%$ in patients with basal $\mathrm{GH}<10 \mu \mathrm{g} / \mathrm{L}$, which may drop to $50 \%$ and $25 \%$ for GH levels $>25 \mu \mathrm{g} / \mathrm{L}$ and $>50 \mu \mathrm{g} / \mathrm{L}$ respectively (14, 17-18). In our series, there was a significant association between surgical outcomes and initial adenoma size, since we found that patients who achieved remission had significantly smaller adenomas at baseline in comparison with those with uncontrolled disease. However, no significant association was observed between baseline GH nadir GH or IGF-I and treatment outcomes.

The importance of an experienced surgeon, exclusively for the pituitary, cannot be adequately stressed. A recent review has shown that focused clinical practice and large transsphenoidal surgical volume appear to be important outcome determinants for patients with pituitary tumors (19). The fact that in our country there is no regionalization of care to higher volume pituitary tumor centers of excellence is a major drawback to better surgical outcomes. Consequently, the lack of better surgical outcomes in our study could partly be attributed to the lack of a single efficiently trained and experienced pituitary surgeon at our region.

Medical therapy as adjuvant to surgery resulted in remission in about half of the patients. Interestingly, all microadenomas and less than half of macroadenomas 
responded to SSA. Improved outcomes with combination therapy have also been reported by others (13). It seems that surgical tumor debulking enhances the response to SSA (20). Moreover, a high proportion of microadenomas (89\%) achieved remission with SSA monotherapy, in contrast to none of macroadenomas. Although the number of these patients was small, the success rates were higher than usually demonstrated (6). More specifically, remission has been reported in up to $80 \%$ of the microadenomas (and intrasellar macroadenomas), but in less than 50\% for larger macroadenomas $(2,6,21-22)$.

Although, there is a wide consensus that TSS is the first treatment choice for patients with acromegaly, SSA are increasingly being used as first-line therapy. Of note, a recent study comparing TSS with octreotide-LAR as first-line therapy in acromegalics (harbouring mainly macroadenomas) reported similar results in terms of optimal disease control at 48-week interval (22). Additional data indicate that SSA monotherapy may offer equivalent biochemical control to secondary treatment after unsuccessful surgery or radiotherapy (23). Furthermore, in terms of adenoma size, shrinkage $>20 \%$ occurs in about $50-75 \%$ of acromegalics receiving SSA $(2,6)$, although this percentage was lower in the present series.

Interestingly, about half of the patients having received SSA in our study developed cholelithiasis, as well as IGT or DM. Gallstones are a frequent entity in acromegalics treated with SSA, may occur at any time, but rarely are symptomatic or require acute surgery (24). In addition, SSAs exert an unfavourable effect on glucose metabolism, due to their inhibitory effect on pancreatic insulin secretion (25), which must be taken into account during therapy.

Conventional radiotherapy is usually used as an adjuvant therapy in pituitary adenomas secreting GH. However, its beneficial effect appears progressively over 
years. It is reported to lead to biochemical control in about $50-60 \%$ of the cases of acromegaly $(2,6)$, which is in line with results of our series. Postoperative radiotherapy was more effective than surgery alone, as also shown in other reports $(13,26)$. Radiotherapy as monotherapy or with adjuvant treatment with SSA was equally successful; however the number of patients was small for safe conclusions. It must be noted that radiotherapy outcomes were manifest at 12-34 years of follow-up, except for 1 patient, who had already achieved remission at 7 years. Consequently, data on radiotherapy can lead to safe conclusions on disease activity ( $>10$ years of follow-up).

Nevertheless, radiotherapy carries some risks that cannot be overlooked such as hypopituitarism, and higher incidence of a second intracranial tumour or cerebrovascular events $(2,6)$. Interestingly, with a longer than 10-year follow-up interval, none of our patients undergoing radiotherapy alone or with SSA experienced hypopituitarism in contrast to $2 / 3$ of those treated with combination of surgery plus radiotherapy and to $1 / 3$ of those with surgery alone.

Successful treatment usually controls the commorbidities associated with acromegaly to variable degrees, but some may persist despite biochemical control (1, 2). However, even partial control of the disease may result in significant improvement of these commorbidities, as we have previously reported (27). Both GH and IGF-I (mainly GH) correlate with mortality and, when they are controlled, mortality is close to the levels expected in the general population (2).

Despite the meticulous data recorded from our department's database throughout the years, we acknowledge the following limitations to our study: 1) it constitutes a retrospective study, but it reflects the "real life" approach and problems of patients with acromegaly in Greece; 2) the number of patients might look small in 
an era of national acromegaly databases, but it derives from the larger endocrine centre of northern Greece and, to our knowledge, this is the first report on Greek population; 3) data on commorbidities were sometimes missing; 4) mortality assessement was not possible.

In conclusion, in this series, acromegaly was characterized by a wide range of systematic complications. Neurosurgery remains the cornerstone of treatment. An increase in remission rates was achieved with complementary conventional radiotherapy. However, the longitudinal risk of postoperative hypopituitarism was higher with this combination. Medical treatment was effective as adjuvant to surgery for macroadenomas and even as monotherapy for microadenomas. Yet, the appearance of cholelithiasis and abnormal glucose homeostasis are important unfavourable events with these agents.

\section{Conflict of interest}

This paper was written independently. The authors did not receive financial or professional help with the preparation of the manuscript.

\section{References}

1. Melmed S. Acromegaly N Engl J Med 2006; 355: 2558-2573.

2. Giustina A, Barkan A, Chanson P, et al; Pituitary Society; European Neuroendocrine Association. Guidelines for the treatment of growth hormone excess and growth hormone deficiency in adults. J Endocrinol Invest 2008; 31: $820-838$.

3. Holdaway IM, Rajasoorya C. Epidemiology of acromegaly. Pituitary 1999; 2: 2941. 
4. Colao A, Ferone D, Marzullo P, Lombardi G. Systemic complications of acromegaly: epidemiology, pathogenesis, and management. Endocr Rev 2004; 25 : 102-152.

5. Dekkers OM, Biermasz NR, Pereira AM, Romijn JA, Vandenbroucke JP. Mortality in acromegaly: a metaanalysis. J Clin Endocrinol Metab 2008; 93: 6167.

6. Melmed S, Colao A, Barkan A, et al; Acromegaly Consensus Group. Acromegaly Consensus Group. Guidelines for acromegaly management: an update. J Clin Endocrinol Metab 2009; 94: 1509-1517.

7. Giustina A, Chanson P, Bronstein MD, et al; Acromegaly Consensus Group. A consensus on criteria for cure of acromegaly. J Clin Endocrinol Metab 2010; 95 : 3141-3148.

8. Giustina A, Barkan A, Casanueva FF, et al. Criteria for cure of acromegaly: a consensus statement. J Clin Endocrinol Metab 2000; 85: 526-529.

9. Bex M, Abs R, T'Sjoen G, et al. AcroBel--the Belgian registry on acromegaly: a survey of the 'real-life' outcome in 418 acromegalic subjects. Eur $J$ Endocrinol 2007; 157: 399-409.

10. Mestron A, Webb SM, Astorga R, et al. Epidemiology, clinical characteristics, outcome, morbidity and mortality in acromegaly based on the Spanish Acromegaly Registry (Registro Espanol de Acromegalia, REA). Eur J Endocrinol 2004; 151: 439-446.

11. Ayuk J, Clayton RN, Holder G, Sheppard MC, Stewart PM, Bates AS. Growth hormone and pituitary radiotherapy, but not serum insulin-like growth factor-I concentrations, predict excess mortality in patients with acromegaly. J Clin Endocrinol Metab; 89: 1613-1617. 
12. Kreutzer J, Vance ML, Lopes MB, Laws ER Jr. Surgical management of GHsecreting pituitary adenomas: an outcome study using modern remission criteria. $J$ Clin Endocrinol Metab 2001; 86: 4072-4077.

13. Beauregard C, Truong U, Hardy J, Serri O. Long-term outcome and mortality after transsphenoidal adenomectomy for acromegaly. Clin Endocrinol (Oxf) 2003; 58: $86-91$.

14. Nomikos P, Buchfelder M, Fahlbusch R. The outcome of surgery in 668 patients with acromegaly using current criteria of biochemical 'cure'. Eur J Endocrinol 2005; 152: 379-387.

15. Biermasz NR, Van Dulken H, Roelfsema F. Ten-year follow-up results of transsphenoidal microsurgery in acromegaly. J Clin Endocrinol Metab 2000; 85: 4596-4602.

16. Abosch A, Tyrrel JB, Lamborn KR, Hannegan LT, Applebury CB, Wilson CB. Transsphenoidal microsurgery for growth hormone-secreting pituitary adenomas: initial outcome and long-term results. J Clin Endocrinol Metab 1998; 83: 34113418.

17. De P, Rees DA, Davies N, et al. Transsphenoidal surgery for acromegaly in wales: results based on stringent criteria of remission. J Clin Endocrinol Metab 2003; 88: $3567-3572$.

18. Fahlbusch R, Honegger J, Buchfelder M. Surgical management of acromegaly. Endocrinol Metab Clin North Am 1992; 21: 669-692.

19. Shahlaie K, McLaughlin N, Kassam AB, Kelly DF. The role of outcomes data for assessing the expertise of a pituitary surgeon. Curr Opin Endocrinol Diabetes Obes 2010; 17: 369-76. 
20. Colao A, Attanasio R, Pivonello R, et al. Partial surgical removal of growth hormone-secreting pituitary tumors enhances the response to somatostatin analogs in acromegaly. J Clin Endocrinol Metab 2006; 91: 85-92

21. Sheppard MC. Primary medical therapy for acromegaly. Clin Endocrinol (Oxf) 2003; 58: 387-399.

22. Colao A, Cappabianca P, Caron P, et al. Octreotide LAR vs. surgery in newly diagnosed patients with acromegaly: a randomized, open-label, multicentre study. Clin Endocrinol (Oxf) 2003; 70: 757-768.

23. Newman CB, Melmed S, George A, et al. Octreotide as primary therapy for acromegaly. J Clin Endocrinol Metab 1998; 83: 3034-3040.

24. Attanasio R, Mainolfi A, Grimaldi F, et al. Somatostatin analogs and gallstones: a retrospective survey on a large series of acromegalic patients. J Endocrinol Invest 2008; 31: 704-710.

25. Ronchi C, Epaminonda P, Cappiello V, Beck-Peccoz P, Arosio M. Effects of two different somatostatin analogs on glucose tolerance in acromegaly. $J$ Endocrinol Invest 2002; 25: 502-507.

26. Trepp R, Stettler C, Zwahlen M, Seiler R, Diem P, Christ ER. Treatment outcomes and mortality of 94 patients with acromegaly. Acta Neurochir (Wien) 2005; 147: 243-251.

27. Delaroudis SP, Efstathiadou ZA, Koukoulis GN, et al. Amelioration of cardiovascular risk factors with partial biochemical control of acromegaly. Clin Endocrinol (Oxf) 2008; 69: 279-284. 


\begin{tabular}{|l|c|c|c|c|c|}
\hline \multicolumn{2}{|l|}{ Table 1. Outcomes of different therapeutic strategies in acromegaly } \\
\hline Therapy & $\begin{array}{l}\text { Total } \\
\text { number } \\
\text { of } \\
\text { patients }\end{array}$ & $\begin{array}{l}\text { Remission } \\
\text { (number } \\
\text { of } \\
\text { patients) }\end{array}$ & $\begin{array}{l}\text { of } \\
\text { patients } \\
\text { with } \\
\text { remission }\end{array}$ & $\begin{array}{l}\text { Microadenomas } \\
\text { (remission/active } \\
\text { disease) }\end{array}$ & $\begin{array}{l}\text { Macroadenomas } \\
\text { (remission/active } \\
\text { disease) }\end{array}$ \\
\hline Surgery alone & 22 & 9 & $41 \%$ & $3 / 3$ & $5 / 10$ \\
\hline Surgery/pharmacotherapy & 30 & 16 & $53 \%$ & $8 / 0$ & $8 / 14$ \\
\hline Surgery/radiotherapy & 8 & 5 & $63 \%$ & $0 / 1$ & $4 / 2$ \\
\hline $\begin{array}{l}\text { Surgery/pharmaco- } \\
\text { /radiotherapy }\end{array}$ & 12 & 4 & $33 \%$ & $0 / 2$ & $4 / 6$ \\
\hline $\begin{array}{l}\text { Surgery/pharmacotherapy/ } \\
\gamma \text {-knife }\end{array}$ & 1 & 1 & $100 \%$ & $0 / 0$ & $1 / 0$ \\
\hline Radiotherapy alone & 4 & 3 & $75 \%$ & $0 / 0$ & $3 / 1$ \\
\hline Radiotherapy/pharmacotherapy & 3 & 2 & $67 \%$ & $0 / 0$ & $2 / 1$ \\
\hline Pharmacotherapy alone & 13 & 8 & $62 \%$ & $8 / 1$ & $0 / 4$ \\
\hline
\end{tabular}

Comments: initial size was not available in 2 patients, 1 of which after surgery alone and 1 after surgery/radiotherapy achieved remission 


\begin{tabular}{|c|c|c|c|c|}
\hline & Baseline & $1^{\text {st }}$ year & $3^{\text {rd }}$ year & $5^{\text {th }}$ year \\
\hline GH ( $\mu \mathrm{g} / \mathrm{L})$ & $24.4 \pm 24.3$ & $12.4 \pm 22.1$ & $6.4 \pm 17.2$ & $5.1 \pm 7.9$ \\
\hline GH nadir $(\mu \mathrm{g} / \mathrm{L})$ & $22.0 \pm 22.1$ & $9.7 \pm 17.7$ & $7.2 \pm 18.9$ & $4.6 \pm 7.1$ \\
\hline IGF-I ( $\mu \mathrm{g} / \mathrm{L})$ & $945 \pm 843$ & $609 \pm 719$ & $372 \pm 278$ & $278 \pm 154$ \\
\hline Adenoma size (cm) & $1.66 \pm 0.90$ & $1.2 \pm 0.7$ & $1.1 \pm 0.6$ & $1.0 \pm 0.6$ \\
\hline
\end{tabular}

